\title{
Xây dựng và thẩm định phương pháp xác định đổng thời 6-benzylaminopurine và forchloríenuron trong giá đỗ bằng kỹ thuật sắc ký lỏng khối phổ hai lần
}

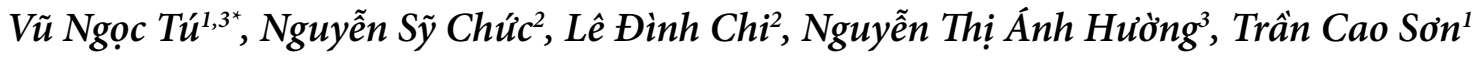 \\ ${ }^{1}$ Viện Kiêm nghiệm an toàn vệ sinh thực phâm Quốc gia \\ ${ }^{2}$ Truờng Đại học Dược Hà Nội
}

${ }^{3}$ Trường Đại học Khoa học Tụi nhiên, Đại học Quốc gia Hà Nội

(Ngày đến tòa soạn: 02/6/2020; Ngày chấp nhận đăng: 30/6/2020)

\section{Tóm tắt}

Việc lạm dụng các chất tăng trưởng thực vật trong nông nghiệp, đặc biệt là các chất có nguồn gốc tổng hợp nhóm cytokinin, có xu hướng ngày càng gia tăng. Trong nghiên cứu này, phương pháp xác định hai chất tăng trưởng thực vật nhóm cytokinin gồm 6-benzylaminopurine và forchlorfenuron trong giá đỗ đã được nghiên cứu xây dựng dựa trên kỹ thuật chiết QuEChERS kết hợp với LC-MS/MS. Điêu kiện sắc ký gôm cột pha đảo $\mathrm{C}_{18}$, pha động ở chế độ gradient với hai kênh $\mathrm{H}_{2} \mathrm{O}$ và $\mathrm{MeOH}$ có bổ sung thêm hỗn hợp acid formic $0,1 \%$ và amoni formate $10 \mathrm{mM}$. Detector khối phổ ba tứ cực, với nguôn ion hóa điện tử dương (ESI+), chế độ theo dõi đa phản ứng $(\mathrm{MRM})$ đã được sử dụng để khẳng định sự có mặt của các chất nghiên cứu. Quy trình xử lý mẫu được tối ưu theo phương pháp QuEChERS sử dụng Acetonitrile $(\mathrm{ACN})$ chứa $1 \%$ acid acetic làm dung môi chiết, PSA làm chất hấp phụ cho hiệu quả chiết tốt. Phương pháp xây dựng có LOQ là 3,0 $\mu \mathrm{g} / \mathrm{kg}$ với độ thu hôi từ 79,1 - 117\%, độ lặp lại từ 3,0 - 7,0\% đạt yêu câuu theo quy định của $\mathrm{AOAC}$ và châu Âu. Phương pháp đã được ứng dụng để phân tích một số mẫu giá đỗ trên địa bàn thành phố Hà Nội, có 5/6 mẫu được phát hiện có 6-benzylaminopurine với hàm lượng vượt giới hạn tồn dư tối đa theo quy định châu Âu.

Tư khóa: LC-MS/MS, QuEChERS, 6-benzylaminopurine, forchlorfenuron, giá đỗ.

\section{1. ĐĂT VẤN ĐỀ}

Giá đỗ là thực phẩm truyền thống của nước ta, được nhiều người ưa chuộng trong các món ăn hàng ngày nhờ hàm lượng dinh dưỡng cao cùng hương vị thơm ngon. Việc sản xuất giá đỗ có thể thực hiện dễ dàng tại các hộ kinh doanh nhỏ hoặc thậm chí tại từng gia đình. Tuy nhiên, cây giá đỗ sản xuất trong điều kiện không sử dụng các chất tăng trưởng thường dài và nhỏ, không bắt mắt do đó người sản xuất bổ sung các chất tăng trưởng thực vật [1]. Trong thời gian vừa qua, đã xuất hiện thực trạng lạm dụng các chất kích thích sinh trưởng trong sản xuất giá đỗ nhằm trục lợi, bất chấp các tác hại đến sức khỏe người tiêu dùng.

Trong các chất kích thích sinh trưởng thực vật, cytokinin là nhóm chất được sử dụng phổ biến trong giá đỗ. Các cytokinin tác dụng lên quá trình phân hóa tế bào, kích thích sự phân chia tế bào mạnh ở thực vật do chúng hoạt hóa quá trình tổng hợp acid nucleic và protein [2]. Tuy nhiên, một số chất cytokinin tổng hợp có thể gây các tác dụng có hại trên người và động vật 
thí nghiệm. Hai chất 6-benzylaminopurine (6-BA) và forchlorfenuron (CPPU), thuộc nhóm cytokinin tổng hợp, không nằm trong Danh mục thuốc bảo vệ thực vật được phép sử dụng do Bộ Nông nghiệp và Phát triển Nông thôn ban hành [3], do đó việc sử dụng hai chất này trong sản xuất giá đỗ là bất hợp pháp. Việc sử dụng 6-BA và $\mathrm{CPPU}$ trái phép trong sản xuất giá đỗ nhiều khả năng vẫn đang diễn ra bất chấp quy định pháp luật hiện hành. Vì thế việc xác định đông thời hai chất này trong giá đỗ rất được quan tâm, góp phân hỗ trợ trong công tác quản lý thị trường, ban hành quy định kiểm soát hàm lượng 6-BA và $\mathrm{CPPU}$ trong sản phẩm giá đỗ.

Nhiều phương pháp đã được xây dựng để xác định tôn dư các chất 6-BA và CPPU, trong đó phương pháp ELISA [4], LC-MS/MS kết hợp cùng quy trình xử lý mẫu bằng kỹ thuật SPE [5], QuEChERS [6-7] được ứng dụng chủ yếu. Phương pháp ELISA thực hiện đơn giản, tiết kiệm, dựa trên việc sử dụng kháng thể đặc hiệu nhận biết cytokinin cho độ chính xác cao. Tuy nhiên phương pháp này không hiệu quả trong việc xác định đông thời các chất do không đáp ưng được yêu cầu về dòng kháng thể đặc hiệu. Phương pháp sử dụng LC-MS/MS được ứng dụng ngày càng nhiều trong phân tích đông thời dư lượng các chất kích thích sinh trưởng do ưu điểm cho độ nhạy và độ chính xác cao, dễ kết hợp với các phương pháp xử lý mẫu, có khả năng xác định nhiều chất đồng thời trong một lần phân tích. Nhiều nghiên cứu [6-8] được công bố đã cho thấy hai phương pháp xử lý mẫu theo kỹ thuật $\mathrm{SPE}$ và QuEChERS đều được ứng dụng hiệu quả để phân tích đông thời 6-BA và $\mathrm{CPPU}$ cho độ thu hồi cao. Tuy nhiên, ứng dụng kỹ thuật SPE yêu câu có pha tĩnh đặc hiệu cho cả 6-BA và CPPU, gây khó khăn trong công tác xử lý thường quy. Trong khi đó, phương pháp QuEChERS yêu cầu kỹ thuật xử lý mẫu đơn giản, tiết kiệm dung môi, thời gian nên được ứng dụng ngày càng rộng rãi.

Trong nghiên cứu này, kỹ thuật xử lý mẫu QuEChERS kết hợp LC-MS/MS đã được lựa chọn để khảo sát xây dựng phương pháp, thẩm định phương pháp và ứng dụng để xác định hàm lượng 6-BA và $\mathrm{CPPU}$ trên nên mẫu giá đỗ.

\section{VÂT LIÊUU VÀ PHƯƠNG PHÁP NGHIÊN CỨU}

\section{1. Đối tượng nghiên cứu}

Hai cytokinin tổng hợp 6-benzylaminopurine (6-BA) và forchlorfenuron (CPPU) được lựa chọn làm đối tượng nghiên cứu. Nền mẫu trong nghiên cứu là giá đỗ. Mẫu trắng giá đỗ được chuẩn bị bằng phương pháp tự trông, các mẫu giá đỗ thực tế được mua từ các chợ trên địa bàn thành phố Hà Nội.

\subsection{Hóa chất}

Chuẩn gốc 6-BA và $\mathrm{CPPU}$ với độ tinh khiết lần lượt 98,51\% và 99,6\% (nguyên trạng) được mua từ hãng Dr. Ehrenstorfer. Các dung môi tinh khiết dùng cho chạy sắc ký gồm methanol, acetonitril, acid formic, acid acetic và các hóa chất $\mathrm{MgSO}_{4}$ khan, $\mathrm{NaCl}, \mathrm{CH}_{3} \mathrm{COONa}, \mathrm{HCOONH}_{4}$ được mua từ hãng Merck; nước cất hai lần được lấy từ máy lọc nước siêu tinh khiết Milli-Q; bột làm sạch d-SPE: bột PSA, bột C18 được cung cấp bởi Agilent.

\subsection{Thiết bị, dụng cụ}

Hệ thống sắc ký lỏng khối phổ hai lần của SCIEX (Mỹ) gồm bơm sắc ký Exion LC 20AD gắn đầu dò khối phổ $\mathrm{AB}$ SCIEX Triple Quad 6500+. Hệ thống được điều khiển bằng phần mềm Analyst version 1.7. Các thiết bị khác bao gồm: Máy đông nhất mẫu (Phillips); cân phân tích chính xác đến 0,01 mg (MS105, Mettler Toledo); cân kỹ thuật, chính xác đến 0,01 g (ME2002T, 
Mettler Toledo), máy ly tâm (Mikro 200R, Hettich); máy lắc xoáy (Vortex 3, IKA) và máy siêu âm (S300H, Elma).

Cột tách sắc ký là cột UPLC BEH C18 (2,1×50mm; 1,7 $\mu \mathrm{m})$, Waters. Các dụng cụ cơ bản trong phòng thí nghiệm: Micropipet tùy chỉnh thể tích từ 10 đến $100 \mu \mathrm{L}$ và từ $100-1.000 \mu \mathrm{L}$ (Eppendorf), bình định mức các loại, ống ly tâm, ống đong.

\subsection{Khảo sát và thẩm định phương pháp}

\subsection{1. Điều kiện LC-MS/MS}

Khảo sát và lựa chọn điều kiện khối phổ: tiêm trực tiếp dung dịch chuẩn hỗn hợp hai cytokinin có nông độ $100 \mathrm{ng} / \mathrm{mL}$ vào hệ thống khối phổ bằng kim tiêm $1 \mathrm{~mL}$. Lựa chọn chế độ ion hóa, ion mẹ, các ion con của hai chất, tối ưu các thông số của thiết bị khối phổ.

Điều kiện sắc ký lỏng: Khảo sát quá trình tách với cột sắc ký pha đảo UPLC BEH C18 $(2,1 \times 50 \mathrm{~mm} ; 1,7 \mu \mathrm{m})$. Khảo sát thành phân và tỉ lệ pha động theo chương trình gradient dung môi với hai kênh: kênh $\mathrm{A}\left(\mathrm{H}_{2} \mathrm{O}\right)$, kênh $\mathrm{B}(\mathrm{MeOH})$, được bổ sung chất tạo nền cho quá trình ion hóa của hệ thống khối phổ. Thực hiện khảo sát hai hệ dung môi có bổ sung acid formic $0,1 \%$ với hệ dung môi có bổ sung hỗn hợp hai thành phân acid formic $0,1 \%$ và amoni formate $10 \mathrm{mM}$.

\subsubsection{Phương pháp xủ lý mẫu}

Phương pháp xử lý mẫu dự kiến ban đầu được tham khảo từ các nguôn tài liệu [6-7] như sau: cân $10,0 \mathrm{~g}$ mẫu giá đỗ đã được xay đông nhất vào ống ly tâm $50 \mathrm{~mL}$ có nắp kín. Thêm $10 \mathrm{~mL}$ dung môi acetonitrile chứa $1 \%$ acid acetic, lắc bằng tay trong $60 \mathrm{~s}$ để đông hóa. Thêm $4 \mathrm{~g} \mathrm{MgSO}_{4}$ khan, $1 \mathrm{~g} \mathrm{NaCl}$, tiếp tục lắc trong $60 \mathrm{~s}$ và ly tâm ở 6.500 vòng/phút trong 5 phút. Hút $3 \mathrm{~mL}$ dịch lớp trên vào ống ly tâm $15 \mathrm{~mL}$ đã chứa sẵn $150 \mathrm{mg} \mathrm{MgSO}_{4}$ và $50 \mathrm{mg} \mathrm{C18}$, lắc xoáy $30 \mathrm{~s}$, ly tâm ở 6.500 vòng/phút trong 5 phút. Hút dịch vào lọ mẫu $2 \mathrm{~mL}$ và phân tích trên thiết bị LC-MS/MS.

\subsubsection{Thẩm định phương pháp phân tích}

Thẩm định phương pháp phân tích được thực hiện theo tài liệu hướng dẫn chuyên khảo kết quả được so với tiêu chuẩn quy định bởi AOAC [8] và Hội đồng châu Âu (SANTE/ 2019/12682) [9]. Các thông số thẩm định gồm ảnh hưởng nền, độ đặc hiệu, giới hạn định lượng, giới hạn phát hiện, đường chuẩn, độ đúng, độ lặp lại.

\section{5. Ûng dụng phương pháp}

Phương pháp đã được ứng dụng để xác định đông thời 6-BA và CPPU trong 06 mẫu giá đỗ được lấy ngẫu nhiên tại các chợ ở Hà Nội.

\section{KẾT QUẢ VÀ BÀN LUÂN}

\section{1. Điểu kiện LC-MS/MS}

\subsection{1. Điều kiện khối phổ}

Sử dụng chế độ ESI (+), tiêm trực tiếp dung dịch chuẩn hỗn hợp có nồng độ $1 \mu \mathrm{g} / \mathrm{mL}$ của 02 chất phân tích để khảo sát các mảnh ion và sự phân mảnh. Kết quả của quá trình phân mảnh được trình bày ở Bảng 1, mảnh ion có cường độ cao hơn được dùng để định lượng. 
Bảng 1. Kết quả phân tách các mảnh và điều kiện tối ưu cho hai cytokinin

\begin{tabular}{ccccc}
\hline Chất phân tích & Ion $\boldsymbol{m e}(\boldsymbol{m} / \boldsymbol{z})$ & Ion con $(\boldsymbol{m} / \mathbf{z})$ & $\boldsymbol{C E}(\mathrm{eV})$ & $\boldsymbol{C X P}(\boldsymbol{V})$ \\
\hline \multirow{2}{*}{ 6-BA } & \multirow{2}{*}{226,1} & $91,1^{*}$ & 33 & 10 \\
& & 65,0 & 73 & 8 \\
\multirow{2}{*}{ CPPU } & \multirow{2}{*}{248,0} & $129,0^{*}$ & 30 & 14 \\
& & 93,0 & 47 & 12 \\
\hline
\end{tabular}

Chú thích: * mảnh định lượng

\subsection{2. Điều kiện sắc kýlỏng}

Chương trình gradient pha động được khảo sát và lựa chọn dựa vào thời gian lưu và hình dạng, độ cân xứng của píc sắc ký. So sánh kết quả từ khảo sát thành phần pha động có bổ sung acid formic $0,1 \%$ với hỗn hợp acid formic $0,1 \%$ và amoni formate $10 \mathrm{mM}$, cho thấy việc bổ sung thêm hỗn hợp acid formic và amoni formate cho hình dạng píc nhọn và cân xứng cho cả 6-BA và $\mathrm{CPPU}$, tỉ lệ thành phần pha động cũng được khảo sát, kết quả trình bày trong Bảng 2.

Bảng 2. Chương trình gradient pha động tối ưu

\begin{tabular}{ccc}
\hline $\begin{array}{c}\text { Thòi gian } \\
\text { (min) }\end{array}$ & $\begin{array}{c}\text { Kênh A } \\
\text { (acid formic 0,1\%, amoni format } \\
\text { 0,1 mM trong nuớc) }\end{array}$ & $\begin{array}{c}\text { Kênh B } \\
\text { (acid formic 0,1\%, amoni format } \\
\mathbf{0 , 1} \text { mM trong MeOH) }\end{array}$ \\
\hline $0 \div 1,5$ & $90 \%$ & $10 \%$ \\
$1,5 \div 4,6$ & $10 \%$ & $90 \%$ \\
$4,6 \div 6,0$ & $90 \%$ & $10 \%$ \\
\hline
\end{tabular}

\subsection{Tối ưu quy trình xử lý mẫu}

Tối ưu hóa quy trình xử lý mẫu tập trung vào khả năng thu được tối đa chất phân tích ở dịch chiết cuối cùng, được thể hiện qua thông số độ thu hồi của chất phân tích. Để đạt mục đích trên, nghiên cứu tập trung tối ưu bốn thông số của quy trình, gồm: dung môi chiết, thời gian và kỹ thuật chiết, loại chất hấp phụ được sử dụng ở bước làm sạch, lượng chất hấp phụ sử dụng.

Trong quá trình xử lý mẫu, có khả năng cao xuất hiện các chất được chiết đồng thời với chất phân tích, tạo ra ảnh hưởng nền làm tăng hoặc giảm tín hiệu của 6-BA và CPPU ở hệ thống khối phổ. Để giảm thiểu ảnh hưởng nên đến kết quả khảo sát điều kiện xử lý mẫu, độ thu hồi được tính theo hiệu suất phân trăm (\%) giữa tín hiệu từ mẫu khảo sát trên tín hiệu mẫu chuẩn trên nền trắng.

Mẫu khảo sát là mẫu được thêm chuẩn trước khi thực hiện quy trình xử lý mẫu theo thông số cần khảo sát. Mẫu chuẩn trên nền trắng là mẫu được pha từ dung dịch chuẩn và dịch chiết của mẫu trắng giá đỗ theo quy trình xử lý mẫu dự kiến.

\subsubsection{Khảo sát dung môi chiết}

Khảo sát so sánh hiệu quả chiết các dung môi: $\mathrm{ACN}, \mathrm{CH}_{3} \mathrm{COOH} 0,1 \%$ trong $\mathrm{ACN}$, $\mathrm{CH}_{3} \mathrm{COOH} 0,5 \%$ trong $\mathrm{ACN}, \mathrm{CH}_{3} \mathrm{COOH} 1 \%$ trong $\mathrm{ACN}, \mathrm{HCOOH} 1 \%$ trong $\mathrm{ACN}$. Kết quả được trình bày ở Hình 1 . 


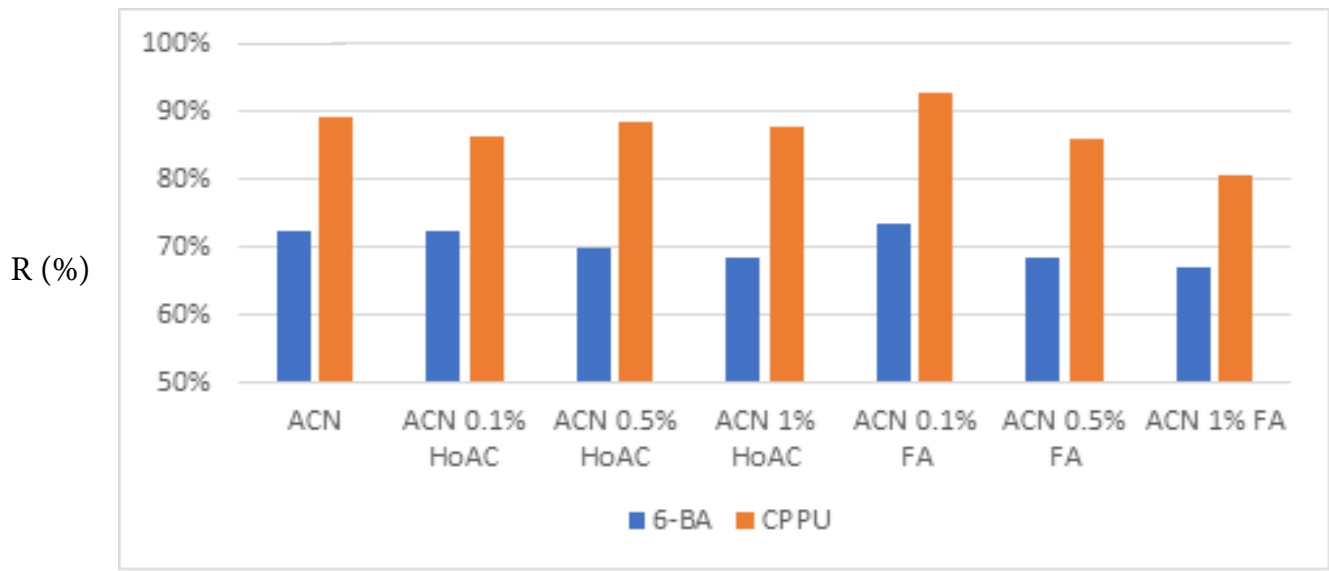

Dung môi chiết

Hinh 1. Biêu đồ khảo sát dung môi chiết

Kết quả cho thấy, khi tăng nông độ acid hiệu suất chiết có xu hướng giảm dần vì nông độ acid cao gây nên sự ion hóa chất phân tích, giảm khả năng phân bố vào pha $\mathrm{ACN}$ khi tách pha $\mathrm{ACN}$ khỏi hỗn hợp với $\mathrm{H}_{2} \mathrm{O}$. Tuy nhiên, ảnh hưởng của acid dung môi đến hiệu suất chiết CPPU không thay đồi nhiều ở các mức acid thấp vì hai chất phân tích đêu có tính base yếu. Vì vậy, $\mathrm{CH}_{3} \mathrm{COOH} 1 \%$ trong $\mathrm{ACN}$ đã được chọn làm dung môi chiết.

\subsubsection{Khảo sát loại chất hấp phụ}

Thay đổi thành phần chất hấp phụ trong bước d-SPE, lần lượt là PSA $(50 \mathrm{mg}), \mathrm{C} 18(50$ $\mathrm{mg})$, PSA: C18 (25 mg : $25 \mathrm{mg})$. Kết quả đánh giá ảnh hưởng của các chất hấp phụ đến hiệu suất chiết được thể hiện ở Hình 2.

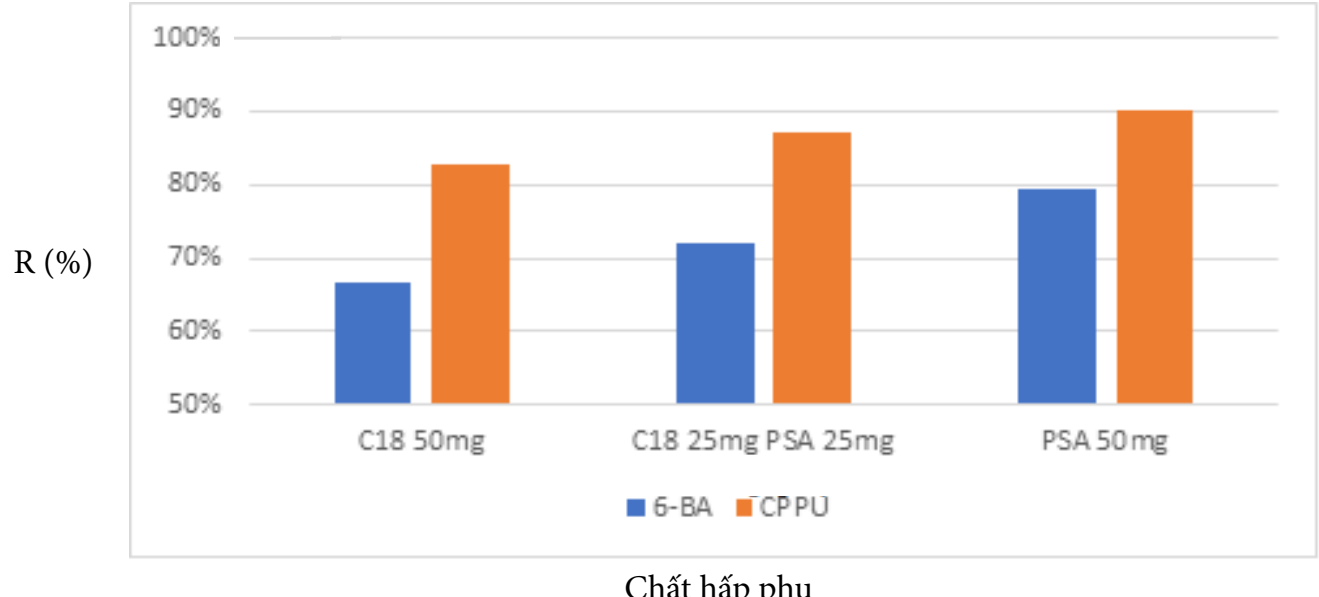

Hinh 2. Biểu đồ khảo sát chất hấp phụ

Kết quả khảo sát cho thấy hiệu suất thu hôi khi sử dụng PSA cao hơn C18. Trong bước d-SPE, yêu cầu về chất hấp phụ tối ưu không chỉ làm sạch nển mẫu mà còn không được hấp phụ gây mất chất phân tích từ dịch chiết. Các cytokinin trong nghiên cứu đều là những chất kém phân cực nên có ái lực với C18 cao hơn PSA. Vì vậy, $\mathrm{C} 18$ có khả năng làm mất chất phân tích gây giảm hiệu suất thu hồi. Thành phần dinh dưỡng tham khảo của giá đỗ gồm có glucid, protid, các vitamin nhóm $\mathrm{B}, \mathrm{C}$, rất ít chất béo. Trong hai chất hấp phụ được khảo sát, PSA có khả năng lưu giữ những chất có bản chất acid, các chất phân cực, $\mathrm{C} 18$ có khả năng lưu giữ những 
chất béo, không phân cực, vì vậy khả năng làm sạch nền mẫu của PSA phù hợp hơn C18. Vì vậy, chọn PSA (50 mg) là chất hấp phụ.

\subsubsection{Khảo sát tỉ lệ lượng chất hấp phụ}

Thay đổi số lượng dịch chiết ban đầu khi hút vào ống d-SPE, lần lượt: $5,4,3,2,1 \mathrm{~mL}$, giữ nguyên lượng PSA ở mức 50 mg. Kết quả được đưa ra tại Hình 3.

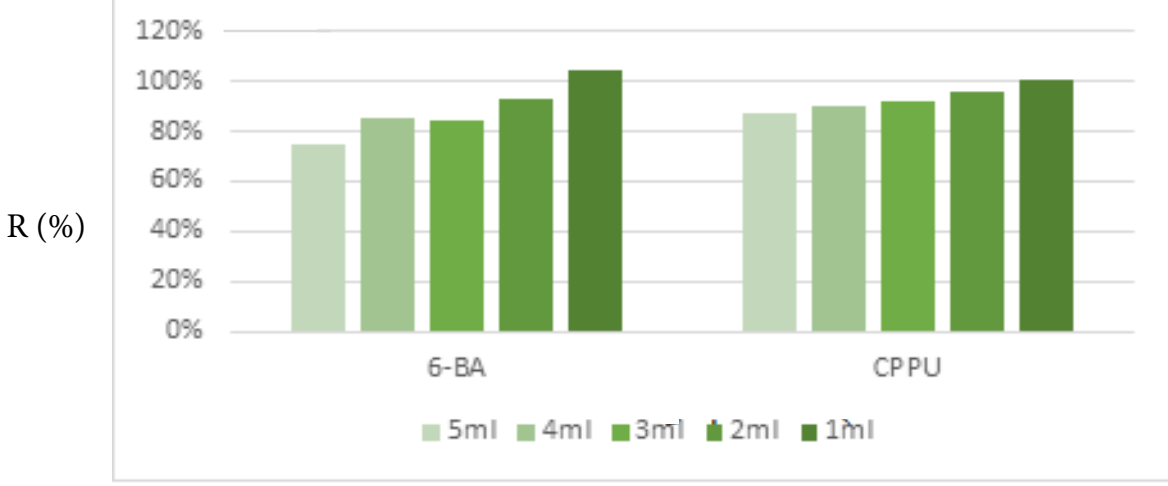

Thể tích dung dịch mẫu $(\mathrm{mL})$

Hình 3. Biêu đồ khảo sát lượng PSA

Kết quả đưa ra ở Hình 3 cho thấy khi giảm lượng dịch chiết cho vào ống d-SPE, đông nghĩa với tăng tỉ lệ lượng chất hấp phụ so với dịch chiết thì tín hiệu thu được tăng lên và đạt khoảng 100\% ở thể tích $1 \mathrm{~mL}$. Vì vây, thể tích dung dịch mẫu $1 \mathrm{~mL}$ đã được lựa chọn mà không tiến hành khảo sát ở các thể tích nhỏ hơn.

\subsubsection{Quy trìn xử lý mẫu tối ưu}

Sau quá trình khảo sát, quy trình xử lý mẫu tối ưu được đưa ra như sau: Cân 10,0 $\mathrm{g}$ mẫu giá đỗ đã được đồng nhất hóa vào ống ly tâm $50 \mathrm{~mL}$ có nút kín. Thêm $10 \mathrm{~mL}$ dung môi $\mathrm{ACN}$, lắc bằng tay trong $30 \mathrm{~s}$ kết hợp siêu âm trong $30 \mathrm{~s}$. Thêm $4 \mathrm{~g} \mathrm{MgSO}_{4}, 1 \mathrm{~g} \mathrm{NaCl}$, lắc tay $60 \mathrm{~s}$, ly tâm ở $6.500 \mathrm{rpm}$ trong 5 phút. Hút $1 \mathrm{~mL}$ dịch lớp trên vào ống đã chứa sẵn $150 \mathrm{mg} \mathrm{MgSO}_{4}$ và $50 \mathrm{mg}$ PSA, lắc xoáy trong $30 \mathrm{~s}$, ly tâm ở $6.500 \mathrm{rpm}$ trong 5 phút. Hút dịch vào lọ mẫu $2 \mathrm{~mL}$ và phân tích trên thiết bị LC-MS/MS.

\subsection{Thẩm định phương pháp}

\subsection{1. Ảnh hưởng nền}

Đánh giá ảnh hưởng nền (Matrix effect - ME) bằng phương pháp dựng hai đường chuẩn cho mỗi chất: mẫu chuẩn trên nền trắng và mẫu chuẩn trên dung môi, so sánh hệ số góc hai đường chuẩn để xem xét ảnh hưởng nển. $\mathrm{ME}$ được tính là chênh lệch của hệ số góc đường chuẩn pha trên nền mẫu so với đường chuẩn pha trên nền dung môi. Kết quả đánh giá ảnh hưởng nền được đưa ra tại Bảng 3.

Bảng 3. Kết quả đánh giá ảnh hưởng nên

\begin{tabular}{ccc}
\hline Cytokinin & ME trung binh (\%) & RSD (\%) \\
\hline 6-BA & $-84 \%$ & 12,1 \\
CPPU & $-73 \%$ & 7,8 \\
\hline
\end{tabular}


Kết quả đưa ra ở Bảng 3 cho thấy ảnh hưởng của nền mẫu lên tín hiệu chất phân tích là rất lớn. Cụ thể, các cytokinin đều chịu ảnh hưởng nền âm làm giảm tín hiệu, vì vậy cần sử dụng đường chuẩn pha trên nền mẫu trắng để tính kết quả phân tích do ảnh hưởng nền vượt quá \pm $20 \%$ theo AOAC [8]. Tuy nhiên, giá trị dao động của ảnh hưởng nền đều nằm trong khoảng cho phép (15\%) cho thấy việc sử dụng đường chuẩn trên nền có thể loại trừ ảnh hưởng nền nhưng vẫn đảm bảo về tính chính xác.

\subsection{2. Độ đặc hiệu}

Sắc ký đồ của mẫu trắng, mẫu thêm chuẩn và mẫu chuẩn pha trong dung môi ở nông độ $20 \mathrm{ng} / \mathrm{mL}$ của hai cytokinin được trình bày trong Hình 4.
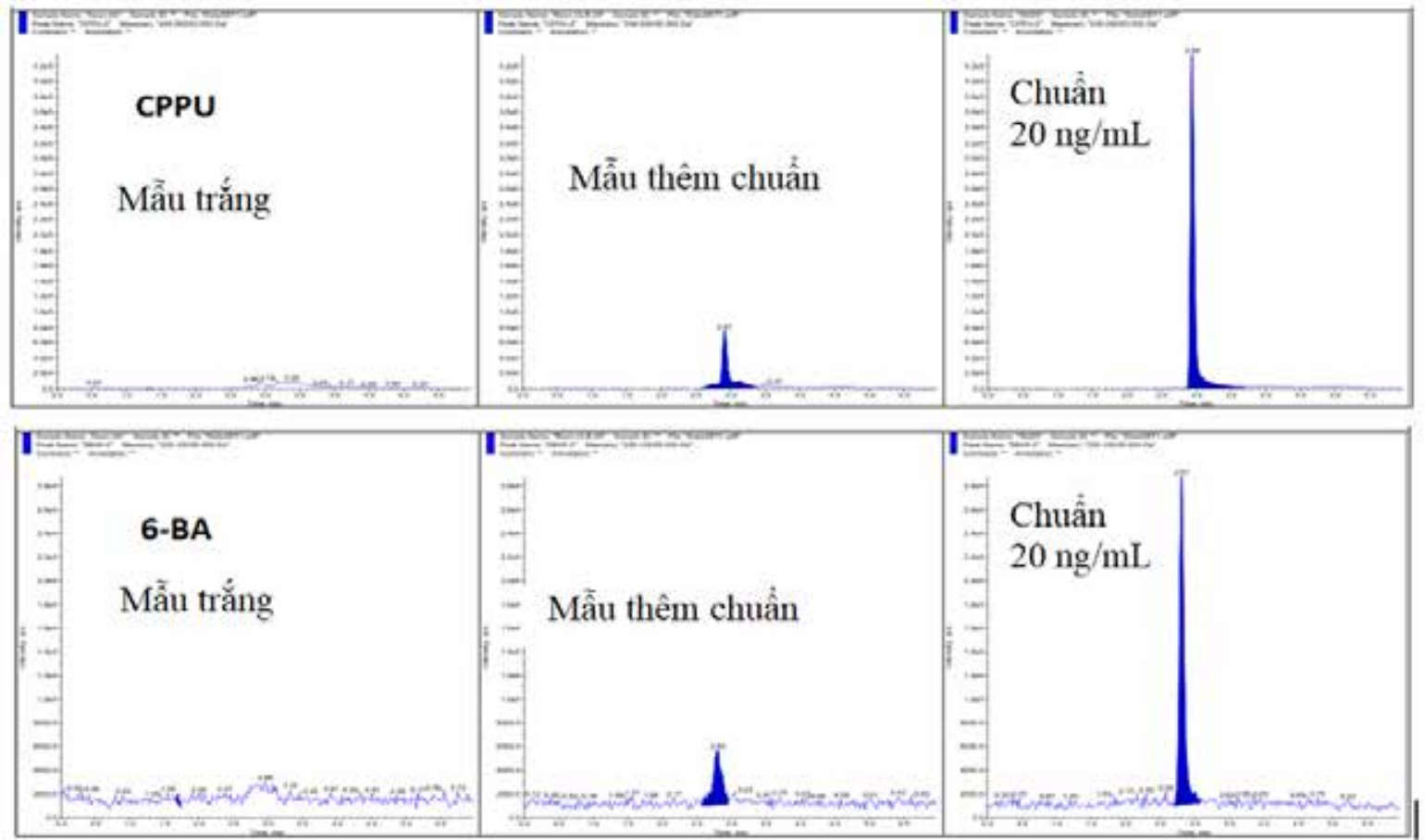

Hinh 4. Sắc ký đồ thâm định độ đặc hiệu chất 6-BA và CPPU

Theo kết quả từ sắc ký đô, thời gian lưu của chất phân tích ở mẫu thêm chuẩn trùng với thời gian lưu trên mẫu chuẩn dung môi, ở mẫu trắng không xuất hiện píc tại thời gian lưu tương ứng, đáp ứng yêu cầu theo tiêu chuẩn của Hội đồng châu Âu [9].

Tỉ số ion và độ lệch của hai Cytokinin trong mẫu thêm chuẩn và mẫu chuẩn dung môi được trình bày ở Bảng 4 .

Bảng 4. Kết quả so sánh tỉ số ion

\begin{tabular}{ccccc}
\hline Chất phân tích & Mẫu thêm chuẩn & $\begin{array}{c}\text { Mẫu chuẩn dung } \\
\text { môi }\end{array}$ & $\begin{array}{c}\text { Độ lệch } \\
\boldsymbol{R}_{\text {diff }}\end{array}$ & Yêu câu \\
\hline 6-BA & $15 \%$ & $12 \%$ & $25 \%$ & $\pm 30 \%$ \\
CPPU & $49 \%$ & $51 \%$ & $-4 \%$ & $\pm 30 \%$ \\
\hline
\end{tabular}

Kết quả đưa ra tại Bảng 4 cho thấy độ lệch giữa mẫu thêm chuẩn và mẫu chuẩn dung môi đều nằm trong giới hạn cho phép trong tiêu chuẩn của Hội đồng châu Âu [9]. 


\subsubsection{Giới hạn định lượng, giới hạn phát hiện}

Thực hiện thêm chuẩn ở các mức nông độ $10,3,0,1,0 \mu \mathrm{g} / \mathrm{kg}$ trên mẫu giá đỗ, xử lý mẫu theo quy trình phân tích để xác định giá trị LOQ và LOQ dựa trên tỷ lệ tín hiệu trên nhiễu $(\mathrm{S} / \mathrm{N})$ lân lượt khoảng bằng 3 và 10 . Kết quả xác định $L O D$ và LOQ được trình bày ở Bảng 5 .

Bảng 5. Giá trị LOQ, LOD của các chất

\begin{tabular}{cccc}
\hline Chất phân tích & LOQ $(\boldsymbol{\mu g} / \mathbf{k g})$ & LOD $(\boldsymbol{\mu g} / \mathbf{k g})$ & MRL Châu Âu $(\boldsymbol{\mu g} / \mathbf{k g})$ \\
\hline $\mathbf{6 - B A}$ & 3,0 & 1,0 & 10 \\
$\mathbf{C P P U}$ & 3,0 & 1,0 & 10 \\
\hline
\end{tabular}

Các giá trị LOD và $L O Q$ đều thấp hơn so với mức giới hạn tồn dư tối đa theo quy định Châu Âu cho thấy phương pháp phù hợp để phân tích các chất trên nền mẫu giá đỗ.

\subsection{3. Đường chuân}

Thực hiện tiêm các mẫu chuẩn pha trên nền mẫu trắng ở các mức nồng độ trong khoảng từ $3-200 \mu \mathrm{g} / \mathrm{kg}$ vào hệ thống LC-MS/MS. Các phương trình đường chuẩn đều có hệ số tương quan $\mathrm{R}$ lớn hơn 0,995 và độ lệch tại các điểm không quá 15\%. Kết quả được trình bày ở Bảng 6 .

Bảng 6. Phương trinh đuiờng chuân

\begin{tabular}{ccc}
\hline Chất phân tích & Phương trình đường chuẩn & Hệ số tương quan $\boldsymbol{R}$ \\
\hline 6-BA & $\mathrm{Y}=8638,4 \mathrm{x}+9651,6$ & 0,9958 \\
CPPU & $\mathrm{Y}=52417 \mathrm{x}-155115$ & 0,9966 \\
\hline
\end{tabular}

\subsection{4. Độ đúng và độ lặp lại}

Thực hiện phân tích các mẫu thêm chuẩn ở 03 mức nồng độ: 3,0, 10, $20 \mu \mathrm{g} / \mathrm{kg}$. Mỗi mức nông độ phân tích lặp lại 06 lần riêng biệt, tính từ bước cân mẫu. Kết quả phân tích độ đúng và độ lặp lại được thể hiện trong Bảng 7 , các độ thu hồi đều nằm trong khoảng 79,1 - 117\% và RSD không quá $20 \%$, chứng minh phương pháp phân tích đáp ứng được yêu cầu về độ đúng và lặp lại theo tiêu chuẩn của $\mathrm{AOAC}$ [8] và Hội đông châu Âu [9].

Bảng 7. Kết quả độ đúng, độ thu hôi

\begin{tabular}{|c|c|c|c|c|c|}
\hline \multirow{2}{*}{$\begin{array}{c}\text { Chất phân } \\
\text { tích }\end{array}$} & \multirow{2}{*}{$\begin{array}{c}\text { Hàm lượng } \\
\mu \mathrm{g} / \mathrm{kg}\end{array}$} & \multicolumn{2}{|c|}{ Độ thu hôi } & \multicolumn{2}{|c|}{ Độ lặp lại (RSD\%) } \\
\hline & & Kết quả (\%) & Yêu cầu & Kết quả (\%) & Yêu cầu \\
\hline \multirow{3}{*}{ 6-BA } & 3,0 & $96 \div 107$ & & & \multirow{6}{*}{$<20 \%$} \\
\hline & 10 & $84,5 \div 95,1$ & $70-120 \%$ & $4,1 \div 7,0$ & \\
\hline & 20 & $106 \div 117$ & (SANTE) & & \\
\hline \multirow{3}{*}{ CPPU } & 3,0 & $100 \div 111$ & $60-115 \%$ & & \\
\hline & 10 & $79,1 \div 87,3$ & $(\mathrm{AOAC})$ & $3,0 \div 6,2$ & \\
\hline & 20 & $105 \div 113$ & & & \\
\hline
\end{tabular}

\section{4. Ửng dụng phương pháp phân tích dư lượng các cytokinin từ các mẫu thực}

Phương pháp được ứng dụng để phân tích 06 mẫu giá đỗ được mua ngẫu nhiên từ các chợ (Đồng Xa, Hà Đông, Xanh, Thượng Đình, Hôm) trên địa bàn thành phố Hà Nội. Kết quả phân tích được đưa ra tại Hình 5. 


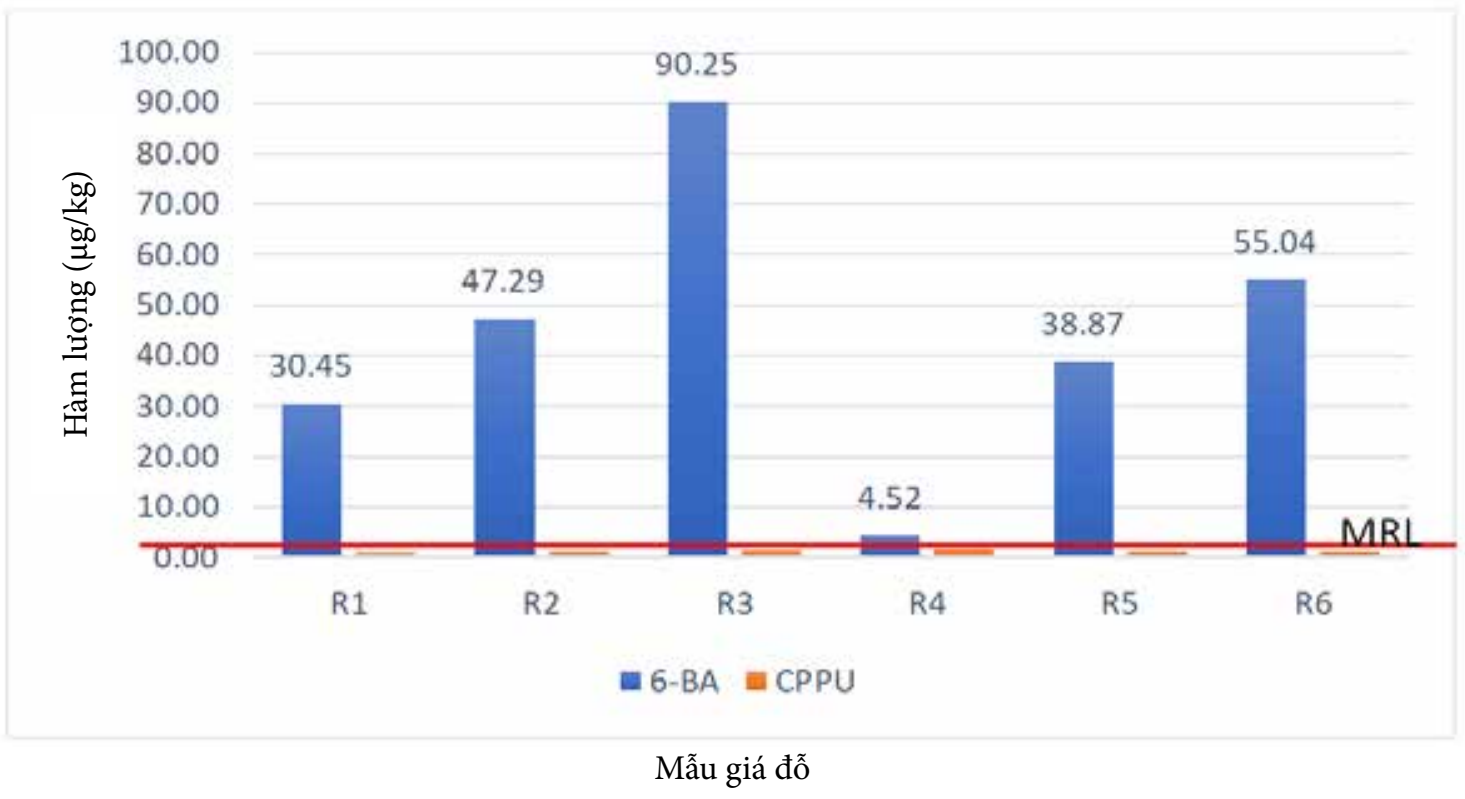

Hình 5. Kết quả xác định hàm lượng 6-BA và CPPU trên mẫu giá đỗ

Kết quả phân tích đưa ra tại Hình 5 cho thấy phát hiện có 6-BA và $\mathrm{CPPU}$ trong cả 06 mẫu. Đặc biệt, hàm lượng của 05/06 mẫu lượng 6-BA phát hiện được vượt quá MRL theo tiêu chuẩn châu Âu [10]. Trong đó, không phát hiện mẫu nào có hàm lượng CPPU cao hơn mức giới hạn dư lượng tối đa (Maximum Residue Level - MRL) theo quy định của châu Âu. Những kết quả thu được trên 06 mẫu này cũng cho thấy việc sử dụng các chất kích thích tăng trưởng thực vật ngoài danh mục cho phép đặc biệt là 6-BA vẫn rất phổ biến. Tuy nhiên, trong nghiên cứu này, số lượng mẫu được phân tích còn quá nhỏ để đưa ra một kết luận mang tính đại diện. Điều này đòi hỏi những nghiên cứu tiếp theo trên số lượng mẫu lớn hơn và trên nhiều nền mẫu khác để có đánh giá đây đủ hơn về việc sử dụng các loại chất kích thích tăng trưởng trong thực phẩm có nguôn gốc thực vật.

\section{KẾT LUẬN}

Phương pháp xác định đồng thời hai cytokinin tổng hợp (6-BA và $\mathrm{CPPU})$ trên giá đỗ đã được xây dựng dựa trên nguyên tắc chiết QuEChERS sử dụng các chất làm sạch gồm $\mathrm{MgSO}_{4}$ và PSA kết hợp với kỹ thuật định lượng bằng LC-MS/MS. Phương pháp đã được thẩm định đạt các tiểu chuẩn của Hội đông Châu Âu và $A O A C$, phù hợp và đủ tin cậy để phân tích các sản phẩm giá đỗ trên thị trường. Kết quả cho thấy sự xuất hiện của 6-BA trong các mẫu giá đỗ với 5/6 mẫu vượt mức giới hạn tồn dư tối đa theo quy định của Châu Âu.

\section{LỜI CẢM ƠN}

Tập thể tác giả trân trọng cảm ơn sự tài trợ kinh phí và cơ sở vật chất của Viện Kiểm nghiệm an toàn vệ sinh thực phẩm Quốc gia để thực hiện nghiên cứu này.

\section{TÀI LIỆU THAM KHẢO}

[1]. A. Basra, Plant growth regulators in agriculture and horticulture: their role and commercial uses, CRC Press, 2000. 
[2]. E. F. George, M. A. Hall, G. J. D. Klerk, "Plant growth regulators II: cytokinins, their analogues and antagonists", Plant propagation by tissue culture, Springer, pp. 205-226, 2008.

[3]. Bộ Nông nghiệp và Phát triển Nông thôn, Thông tủ ban hành Danh mục thuốc bảo vệ thực vật được phép sử dụng, cấm sử dụng tại Việt Nam, Hà Nội, 2019.

[4]. W. Zhang, L. He, R. Zhang et al., "Development of a monoclonal antibody-based enzymelinked immunosorbent assay for the analysis of 6-benzylaminopurine and its ribose adduct in bean sprouts", Food Chemistry, vol. 207, pp. 233-238, 2016.

[5]. F. Wang, W. Zhang, Y. Chen et al., "Simultaneous determination of six plant growth regulators in fruits using high performance liquid chromatography based on solid-phase extraction and cleanup with a novel mixed-mode functionalized calixarene sorbent", Analytical Methods, vol. 7, no. 15, pp. 6365-6371, 2015.

[6]. S. Liu, Y. Wu, C. Fang, Y. Cui, N. Jiang \& H. Wang, "Simultaneous Determination of 19 Plant Growth Regulator Residues in Plant-originated Foods by QuEChERS and Stable Isotope Dilution - Ultra Performance Liquid Chromatography-Mass Spectrometry", Analytical Sciences, vol. 33, no. 9, pp. 1047-1052, 2017.

[7]. L. Ma, H. Zhang, W. Xu et al., "Simultaneous determination of 15 plant growth regulators in bean sprout and tomato with liquid chromatography-triple quadrupole tandem mass spectrometry", Food Analytical Methods, vol. 6, no. 3, pp. 941-951, 2013.

[8]. AOAC Official Methods of Analysis, Appendix F: Guidelines for standard method performance requirements. 2012.

[9]. European Commission, Method Validation and Quality Control Procedures for Pesticide Residues Analysis in Food and Feed, SANTE/12682/2019, 2019.

[10]. European Commission, Maximum residue levels of pesticides in or on food and feed of plant and animal origin and amending Council Directive 91/414/EEC, EC 396/2005, 2005.

\title{
Development and validation of LC-MS/MS method for simultaneous determination of 6-benzylaminopurine and forchlorfenuron in bean sprout
}

\author{
Vu Ngoc Tu ${ }^{1,3}$, Nguyen Sy Chuc ${ }^{2}$, Le Dinh Chi', Nguyen Thi Anh Huong ${ }^{3}$, Tran Cao Son ${ }^{1}$ \\ ${ }^{1}$ National Institute for Food Control, Hanoi \\ ${ }^{2}$ Hanoi University of Pharmacy \\ ${ }^{3}$ University of Science, Vietnam National University, Hanoi
}

\section{Abstract}

The overuse of plant growth promoters in agriculture, especially those derived from a synthetic cytokinin group, is increasing rapidly. In this study, the method for determining two plant growth hormones of the cytokinin group, including 6-benzylaminopurine and forchlorfenuron in bean sprouts, was developed based on the QuEChERS extraction technique in combination with LC-MS/MS detection and quantification. Chromatographic conditions 
include C18 reversed phase column, a gradient mobile phase system with two channels of $\mathrm{H}_{2} \mathrm{O}$ and $\mathrm{MeOH}$, with the addition of $0.1 \%$ formic acid and $10 \mathrm{mM}$ amonium formate. Triple quadrupole mass spectrometry detector, with positive electrospray ionization source (ESI+), multiple reaction monitoring (MRM) mode, was used to confirm the analytes' presence. The sample preparation process was optimized using QuEChERS approach with acetonitrile as an extraction solvent, PSA as adsorbent. Method validation data includes the LOQ of $3.0 \mu \mathrm{g} / \mathrm{kg}$, the recoveries from $79.1-117 \%$, and the repeatability relative standard deviation from 3.0 $7.0 \%$, which meets the requirements of AOAC and European Union. The method was applied to analyze some bean sprouts samples in Hanoi city, 5 out of 6 samples were found to contain 6-benzylaminopurine with the content exceeding the EU's maximum residue limit.

Keywords: LC-MS/MS, QuEChERS, 6-benzylaminopurine, forchlorfenuron, bean sprout. 